\title{
Financial Management and Gender Equality in Interscholastic Athletics
}

\author{
Steve Chen ${ }^{1, *}$, Aaron Willoughby ${ }^{2}$, Kenneth Henderson ${ }^{1}$, Shannon Callihan ${ }^{1}$ \\ ${ }^{1}$ College of Business and Technology, Morehead State University, Morehead, United States \\ ${ }^{2}$ Estill County Elementary School, USA
}

Copyright $(\subset 2015$ by authors, all rights reserved. Authors agree that this article remains permanently open access under the terms of the Creative Commons Attribution License 4.0 International License

\begin{abstract}
Interscholastic athletic programs must avoid gender-based budgetary inequity lawsuits to ensure their successful operation. Potential problem areas are the methods used to generate athletic funds, female sports funding and the maintenance of Title IX compliance. Eighty-two interscholastic athletic directors from eastern Kentucky region shared their perceptions concerning these potential problem areas. They completed an online survey based on past literature [1, 2, 3] addressing themes concerning effective strategies for generating athletic funds and maintaining equitable athletic budgets for both gender sports. The results indicated that participants adopted both direct sales (food, apparels, and tangible product items) and indirect sales (advertising spaces, conducting camps, and offering services) to generate revenues for their athletic programs. They had adopted the popular fundraising methods which were commonly suggested by past literature. In general, participants also agreed that female students should receive necessary financial support and opportunity to accommodate their participatory need. It is suggested that keeping an accurate Title IX report is the key to ensure a high level of Title IX compliance. Potentially the most controversial finding is that participants prefer to keep the majority of funds for football and men's basketball.
\end{abstract}

Keywords Gender Equity, Interscholastic Athletics, Fundraising

\section{Introduction}

Title IX compliance and fundraising are probably the most critical issues that athletic administrators may face. These issues impact successful interscholastic athletic programs [4]. Recent economic crises have exacerbated these challenges. Without adequate funding and proper funding distribution based on gender equality, female athletic participation is especially impacted.

In order to comply with the essence of Title IX, an athletic program must have effective strategies to generate revenues and funds to support operational needs. Coaches and athletic directors must be knowledgeable funds raisers in order to effectively meet the needs of both male and female athletes. Without these fund raising skills, their managerial tasks become extremely difficult and cumbersome.

Interscholastic sports are a vital part of secondary education and provide entertainment activities that draw community fans to support and attend events. Athletic participation is often viewed as learning experience that teach students about unity, team-work, integrity, courage and other moral lessons (i.e., dealing with failure) [5]. Despite these positive factors, district-wide budget and resources that support interscholastic athletics are severely inadequate and dwindling.

The conundrum faced by athletic administrators is how to afford athletic administrators new technology, equipment and improve facilities. Without a wealthy athletic budget to build the foundation of sport programs, success is virtually impossible to achieve. The report of National Interscholastic Athletic Administrators Association [6] indicated two-third of surveyed schools experienced a reduction in the athletic budget. Administrators and coaches are pressured to win more while complying with Title IX and a reduced budget. In fact, a recent study found $82 \%$ of administrators and coaches felt the pressure of budget constraint [6] as they strove to equally support both gender while allocating and distributing funds under Title IX regulation.

\section{Financing athletic programs in colleges and high schools}

The most three common methods for financing interscholastic programs in United States are fundraising (87\%), sponsorship (57\%), and participation fee $(37 \%)$ [3; 7]. Fundraising is a method of generating revenues for a specific purpose in mind. It can be used for a variety of reasons with many creative ideas. There are several ways that sport teams put it to a good use. According to Newell [2], there is no exact science to fundraising in athletic programs. Methods and ideas for fundraising are all relative and flexible due to the target demographics, availability of time, consumers' 
preference, and sellers' effort. For example, an athletic director's car wash may be another coach's candy sale. Revenues from fundraising can be classified as direct (restricted) and annual fundraising [2].

\section{Fundraising methods}

Direct fundraising is essentially composed of donations and financial support from fans for a specific sports team or program. This method does not require the athletes to sell products (i.e., hosting a bake sale) or perform service (i.e., doing car wash). In fact, it requires little effort from athletes. Beth Coyle of Notre Dame High School in Lawrenceville, $\mathrm{NJ}$, who supports direct fundraising, once stated, "A lot of people aren't contributing to annual appeals. They would much prefer to give to a restricted fund." $[2$, p. 6] Notre Dame High School's most successful appealing technique used by the head football coach is the "Friends of Irish Football" event. It is a simple program that fans and supporters can donate money to the football program. Amazingly, this donation program alone can generate \$20,000-30,000 annually [2].

The other primary fundraising method is the annual fundraising that comprises many seasonal programs throughout the year. This type of fundraising method often requires athletes to sell and conduct services. Athletes may need to sell candy bars, work bingo halls, collect donations in person, host lift-a-thons, or participate in other activities [2].

Past literature has documented many different fundraising ideas adopted by the college and high school athletic directors and coaches. At the collegiate level, fundraising can take a variety of approaches, including donations and booster support. According to University of Arizona's former Athletics Director Jim Livengood, 80 percent to 85 percent of his job consists of looking for new revenue sources" [8]. The success of booster programs and donation has proven, since University of Arizona raised more than $\$ 9.23$ million in fiscal year 2002-2003. Donations and funding came from more than 5,000 contributors throughout the country with various methods such as cash/credit card payment, matching gifts, endowments, and life income gifts. There were 75 individual donations, 22 corporate or group donations, and one anonymous donation with each greater than $\$ 20,000$ in amount [8].

At the high school level, booster club funding is a revenue generating tool adopted by more than $50 \%$ of the schools that may accounted for $10 \%$ of the athletic budget [6]. Booster support has led to growing ethical concerns with universities, since there is so much money and potential risk of violating National Collegiate Athletics Association rules involved. Universities must ensure that their athletes and coaches are aware of these concerns when dealing with booster support. As Mr. Livengood stated, dealing with boosters has become a constant daily struggle [8].

While fundraising activities for middle/high school sports may not generate the large amounts of money like college programs, they can still raise significant amount of money to support athletic programs. For examples, Midwest City High
School of Oklahoma had hosted golf tournaments for more than decades for their football, baseball and wrestling program. The tournament alone could raise $\$ 10,000$ or more in one day [9]. Golf scramble is a very popular fundraising event utilized by many schools [7]. Ten-thousand dollars is a huge amount of money for any high school sports program to raise that requires only one day of hard work. Schools can gain most of their profits through the hole-sponsors. Business may pay up to $\$ 50-100$ to have their name as a hole-sponsor [9]. Van Milligen further proposed the selling radio broadcasting ads and special charge for parking spots for revenues [10].

In addition to golf scrambles, many schools and programs implement other fundraising activities such as car washes, cookie dough sales, shoot-outs for basketball [11]. Many schools also use concession food sales at sporting events. The operation of those sales often is managed by the parents of athletes.

\section{Sponsorship methods}

Revenues generated through sponsorships are extremely popular and profitable for mega sport events, tournaments, and professional sports [12]. This trend also has gained popularity at collegiate and high school levels. Forsythe [13] indicated that local vendors and companies often are very generous in sponsoring high school athletics in order to show their support to the community. The need of compliance with Title IX has encouraged interscholastic athletic administrators engaging in sponsorship to seek resources for funding rising female programs $[12,14]$. According to Hall and Gibson [15], the percentage of high school athletic programs using corporate sponsors has increased from $50 \%$ in 2000 to $62.5 \%$ in 2004 . The amount of sponsorship could range as high as $\$ 1,000-\$ 5,000$. Although it is rarely mentioned, there are also naming rights deals existing for high school athletic facilities that worth more than $\$ 100,000$ [16-17]. These large amount of corporate sponsorship deals have caused scholars worry about interscholastic athletics being over-commercialized [5]

\section{Participation fee methods}

Pierce \& Bussell's national survey [3] on 360 high school administrators showed that $34.1 \%$ of schools charged participation fees. The utilization of participation fees in supporting athletic programs has grown rapidly since 2009 [7]. The cost of participation fees varied depending on location of the program, type of sport, participant's' financial status, and number of sports an individual has participated. In general, they ranged from $\$ 150$ to $\$ 350$ s [7].

\section{Equity concerns in athletic funding}

The establishment of Title IX in 1972 prohibited female participants from being discriminated against or denied benefits of education programs or activities that receive federal financial assistance. This legislation has served as the guidelines for providing equal athletic opportunity and funding for both genders. To address the issue of Title 
compliance, federal agencies or athletic governing bodies examine three main areas, namely (1) accommodation of interests and abilities, (2) athletic financial assistance and scholarship availability, and (3) other program areas [18]. The majority of complaints are filed against the accommodation of interests and abilities standard.

To determine the actual level of compliance in gender equity in collegiate athletics, Kenney developed an index that focused on five criteria: participation number (based on proportionality), scholarship availability, operating expenses, recruitment budget, and coaching salaries [19]. According to Kennedy's findings [19], gender inequity was clearly shown in Division-I athletics. Female students who accounted for $41 \%$ of total participation only received $38 \%$ of total operating budget. The study found 31 conferences failed to maintain an operating budget that is proportionated to the female student-athletes. According to Benita Fitzgerald Mosley, former president of the Women's Sports Foundation, $80 \%$ of US colleges are not in compliance with Title IX and the percentage of non-compliance is even high at the high school level [20]. These findings belie the myth that profitable football and basketball programs can provide sufficient revenues to promote and sustain women's sports.

There are also major discrepancies regarding the interpretation of gender equity indicated by Title IX. For example, the American Sports Council would argue that Title IX only applies to collegiate and university athletics. According to Neena Chaudhry, senior counsel of the National Women's Law Center, schools of all levels are finding a way to weaken Title IX so they will not be accused for violating the essence of gender inequity [1].

Examples of gender inequity and Title IX incompliance in athletics at the high school level are ongoing and prevalent. Schools have been sued for being discriminatory in scheduling women's competitions for unfavorable time and providing inadequate transportation service [20]. In Georgia, Michigan, Oklahoma and Washington, cases related to gender discrimination were filed regarding to the facility use as girls often were left to practice and play on an older and poorly maintained facility $[4,20,21]$. There are many examples of booster clubs lavishing their funds on male sports' equipment and needs (particularly in football and basketball), but insignificant funds spent on female programs [4]. Although local school boards would like to have more control over the private funds provided by the booster for the purpose of monitoring gender equity, those boosters often resist this idea and wish to retain the funds for their specific sport.

Donna Lopiano, former executive director of the Women's Sports Foundation, contends that state athletic association and national sport governing bodies (i.e., NCAA) should play a vital role in ensuring gender equity in athletics $[21,22]$. Apparently, high school athletics do not need to disclose equity information and often escape Title IX scrutiny [21]. According to Kiely [1], surveys can be used as a valuable tool to monitor Title IX compliance. Eric Pearson, executive director of the College Sports Council, welcomes any surveys as viable alternatives to document the gender quota and student interests [1]. Kentucky's mandatory audit report on athletic finance seems to be an effective practice to address gender inequity and is supported by many administrators.

\section{Purpose and significance of the study}

Overall, maintaining Title IX compliance should be a high priority issue that must be taken seriously by school athletic directors [20,22]. Although offering a wide variety of sports with equal opportunity for both males and females is essential to building successful sports programs critics of Title IX assume this legislation has inadvertently led to the elimination of some men's college sport programs [23]. Past literature shows violations of funding equity based on gender in college and high school athletes are clearly evident and growing [4, 19, 23]; however, Title IX compliance in equal funding distribution for athletics seems to an issue that is addressed in collegiate athletics while high school athletic associations usually are able to escape Title IX scrutiny [21]. Although generating more funds and complying with Title IX should be top concerns for the interscholastic athletic directors, few studies simultaneously focus on these two issues. Despite fundraising is the most common way (87\%) for the high school programs to generate funds [3], the existing information on their effectiveness and adoption rate of various strategies are anecdotal. In this study, the researchers recognize primary effective methods that high school athletic directors (ADs) have used to finance their programs. In additional, the researchers examined those ADs' perception of gender equity related to sport participation and funding. The findings of the study should help a specific state high school sport federation to recognize the current administrators' philosophy and position on gender-equity concern and provide recommendations to deal with funding inequity.

\section{Method}

This study took a convenience sampling approach to reach out to all of 277 athletic administrators of all Kentucky High School Athletic Association (KHSAA). The researchers created an email list of those administrators whose contact information was posted in the official site of the KHSAA. An electronic invitation was sent to each $\mathrm{AD}$ to complete the online survey posted in Survey Monkey. After collecting all of the survey responses, the actual participants included 82 interscholastic athletic directors (many of them are coaches as well; 62 males and 20 females). It yielded a $29.6 \%$ of rate of return. Among the 277 contacted $\mathrm{AD}$, there were only 30 of them females. This means this study had included the responses of $67 \%$ of the current female directors. The online survey was created based on the essence of several past studies $[1,2,3]$ related to two themes: (1) ideas and viewpoints on revenue generating methods, and (2) perceptions toward female sport participation and funding 
distribution based on gender-equality concern. It contained eight open-ended questions (see Table 1 for details) and 10 five-point Likert scale items. In general, the open-ended questions concentrate on two major themes: (1) identification of participants' concerns in promoting female sports and sharing funds equally for both genders, and (2) identification of strategies, effectiveness, and values toward to athletic fundraising. The Likert scale items are ten statements related to the aforementioned themes covered by the open-ended questions as well. The participants would be able to rate their level of agreement on each of the listed statement ranging from strongly agree (1) to strongly disagree (5).

The survey contents were further reviewed by a panel of sport management faculty $(\mathrm{n}=4)$.

A focus group consisted of six coaches and athletic directors from Powell and Estill County School Districts in Kentucky provided their feedback concerning the wording of the questions. The data were collected from March, 2014 to Mid-April of 2014. Our original goal was to reach at least $33 \%$ of total invitees to respond. The study actually yielded a $29.6 \%$ of return rate.

Table 1. List of open-ended questions

1. What are some ways that you (as an athletic director) can ensure that your sport programs are in compliance with Title IX? What are the main challenges that hinder your program from complying with Title IX?

2. Are your fundraising programs generally coordinated by the coaches, or do you offer and plan ideas, and require teams to implement them?

3. How do you ensure that funding is equally distributed throughout programs? Or are they?

4. Are there any specific strategies that you have, or implement, that attempt to stimulate growth of female sports?

5. What are some programs that your teams use to generate revenue for uniforms, equipment, and other needs?

6. Which programs that you have used have proven to be the most successful? Explain why you think they were successful?

7. In response to female athletes looking to participate in male dominant sports (football, baseball), what is your opinion on this matter? Should they be granted permission to participate alongside male athletes if there are no "female only" sports of the type, even if there are safety concerns?

8. What are some of your future plans that will help generate funds for your sports teams, as well as your school district through increasing fan growth?

\section{Qualitative responses}

A total of 63 participants offered their opinions on the open-ended questions. The results provided some insightful information to help researchers understand the participants' view on gender equity and attitude toward fundraising. In general, the overall consensus among the athletic directors supported the idea of maintaining good communication on gender equity related data between the coaching staff and athletic directors. One of the major challenges faced by the participants was the difficulty of a single individual monitoring female athletic participation and budget. This important responsibility should be a joint task shared among all coaches and ADs.

About one-third of participants indicated that fundraising proposals required approval from the athletic directors and school principals; however, the actual activities are coordinated by the boosters and coaches.

In order to ensure the gender equity in funding, the completion of the Kentucky High School Athletics Association (KHSAA) Title IX report form is the best strategy recognized by all schools. This report is a mandatory requirement that must be submitted in every five years during an audit period. The report may reflect whether a school is working to develop sports programs for both genders and share the budget evenly. This financial report also covers the reports submitted by the booster programs. Every response mentioned that male sports have always drawn larger crowds than female sports. Several recommendations were proposed to build fan support for the female sport programs. These recommendations include inviting community groups and youth teams to attend games. Little league baseball teams, basketball groups, cheerleading clubs, and dance teams should be invited to attend ladies' games. This approach will also attract many families who will attend the event to watch their children participate in half-time activities. Female basketball is a growing sport that has its own season at the junior high level. Perhaps arranging different seasons for female sports may generate more attention and draw in a larger crowd. Many mentioned that female softball teams also have their own playing field. Schools are offering a variety of female sports to encourage participation. Although there are less female participants in this study, they provided more comments on how revenues or funds should be monitored and shared equally than males did. Female ADs also gave more suggestions and comments on how to increase the attendance and revenues of female sports.

Regarding to the revenue generating strategies, Table 2 display an extensive results of methods (27 key methods) that are commonly applied by the participants' programs. The perceived most effective methods (10 items) are also identified. Based on the listed methods, the researchers categorized them into three main groups: (1) tangible product and item sales (i.e., foods, apparels, drink, programs, tickets, etc.), (2) services and activities (dinners, camps, tournaments, car wash, and adopt a highway, etc.), and (3)

\section{Results}


donation, sponsorship, and commercials. The top-3 most commonly adopted revenue generating methods were: (1) concession sales, (2) apparel sales, and (3) donation/sponsorship. The top-3 profitable methods identified were: (1) golf scrambles, (2) candy bars sales, and concession sales.

Table 2. Methods for generating revenues for the athletic programs

\begin{tabular}{|l|l|}
\hline \multicolumn{1}{|c|}{$\begin{array}{c}\text { Summary of Identified Methods } \\
\text { Concession sales (18) }\end{array}$} & \multicolumn{1}{c|}{$\begin{array}{c}\text { Most Profitable Methods } \\
\text { (Number of votes) }\end{array}$} \\
\hline $\begin{array}{l}\text { Apparels sales: T-shirt and hoodie sales } \\
\text { (18) }\end{array}$ & \\
Donation/sponsors (17) \\
Candy bars (15) \\
Trash pick-up/adopt a highway (12) \\
Golf scrambles (12) & \\
Ads-Gym billboards (12) & Golf scrambles (11): gets \\
Bingo (11) & full support from the \\
Cookies (10) & booster clubs, large profits, \\
and has low cost if the fees \\
Campot-a-thon (basketball) (9) & are donated \\
Chili soup dinners (8) & Candy bars: easy to sell (9) \\
Fee charges (7) & Concession sales (8): have \\
Game Programs (6) & three night games, people \\
Candles sales (4) & get hungry and thirsty \\
Kettle Korn (4) & Sponsors (8): they like to \\
Firework sales (4) & support relatives \\
Car wash (4) & Program sales (4) \\
Pizza (4) & Apparels (4) \\
Auction (4) & Tournaments (4) \\
Adopt a highway (4) & Ads sales (4) \\
Kona Ice (3) & Discount cards (2) \\
Spirit items sales (umbrella, pennant) (2) & Service done by athletes \\
Bringing younger children to the sports & (2) \\
games (2) & \\
Discount card/Coupon (2) & \\
Gate receipt (2) & \\
Fruit sales (1) & \\
\hline & \\
\hline
\end{tabular}

The participants were asked to common on the view of allowing female athletes looking to participate in male dominant sports. This question was intended to test how far an individual would stretch his/her gender equity definition. The results on this matter were very interesting. Thirty-four participants completely agreed that female athletes should be given the opportunity to participate in male dominant sports as long as they were made aware of the risks and they were good enough. Fourteen participants expressed a view of "maybe." They seemed to be held back by the safety and risk concerns and potential sexual harassment issues. There were fifteen participants disapprove the idea of allowing females to compete in male sports. Some felt that female athletes wouldn't have the commitment to stick around through the season once they realized the required demands. Three participants expressed that the current rules implemented in their district regarding male and female sports were working just fine, so women should just play with women due to safety issues. Three participants were against co-ed sports, since they claimed females have a different emotional and physical makeup than male athletes.

Regarding the future plans for generating funds, participants expressed their eagerness to look for the "next big thing", and will try any niche that is financially driven. This suggests more fundraising activities will be incorporated. The top-three future fundraising choices identified are sport camps $(n=15)$, steak dinner with entertainment for several different occasions $(\mathrm{n}=12)$, and sponsorship $(\mathrm{n}=8)$. Other mentioned activities include: babysitting services, half-time shot contest, community services, apparel sales, discount cards, and $5 \mathrm{Ks}$ races. There is one comment specifically addressing the need of creating one booster club to allocate and distribute the funds centrally.

\section{Quantitative analyses}

Table 3. Perceptions relating to revenue generation and gender equity in high school athletics (1: strongly agree; 5: strongly disagree)

\begin{tabular}{|c|c|c|}
\hline $\begin{array}{l}\text { Item and Factor (Cronbach } \alpha \text { and } \% \text { of } \\
\text { variance) }\end{array}$ & M & S.D. \\
\hline Fundamental beliefs $(\alpha=.644 ; 24.8 \%)$ & 2.41 & 0.91 \\
\hline $\begin{array}{l}\text { Q1. Female athletes should be permitted to } \\
\text { play with male athletes }\end{array}$ & 2.8537 & 1.2361 \\
\hline $\begin{array}{l}\text { Q3. Male sports generate more revenue for } \\
\text { our school than females' }\end{array}$ & 1.8780 & 1.1444 \\
\hline $\begin{array}{l}\text { Q8. Fundraising should take place year } \\
\text { round (including the off season) }\end{array}$ & 2.4878 & 1.2067 \\
\hline $\begin{array}{l}\text { Factor 2. Revenue sharing concepts } \\
(\alpha=.584 ; 26.8 \%)\end{array}$ & 2.96 & 1.07 \\
\hline $\begin{array}{l}\text { Q6. All teams for both genders should } \\
\text { share their revenue from fundraising } \\
\text { equally }\end{array}$ & 3.8293 & 1.0223 \\
\hline $\begin{array}{l}\text { Q7. Revenue sharing ideas have proven to } \\
\text { be critical }\end{array}$ & 2.5366 & 1.0024 \\
\hline $\begin{array}{l}\text { Q9. Sponsorship money equally go to both } \\
\text { gender programs }\end{array}$ & 2.5122 & 1.1858 \\
\hline $\begin{array}{c}\text { Factor 3. Revenue distribution practices }(\alpha \\
=.701 ; 17.0 \%)\end{array}$ & 2.13 & .63 \\
\hline $\begin{array}{l}\text { Q2. Female sports should receive the same } \\
\text { amount of funds as male sports }\end{array}$ & 1.3659 & .6617 \\
\hline $\begin{array}{l}\text { Q10. Sponsors can determine which } \\
\text { gender team their money go }\end{array}$ & 2.8750 & 1.3241 \\
\hline \multicolumn{3}{|l|}{ Items do not fit in a factor } \\
\hline $\begin{array}{l}\text { Q. } 4 \text { Revenue should stay with that } \\
\text { "specific" team that raise the fund }\end{array}$ & 3.6585 & 1.1960 \\
\hline $\begin{array}{l}\text { Q5. Coaching staff should be entirely } \\
\text { responsible for team fundraising }\end{array}$ & 3.6829 & 1.1278 \\
\hline
\end{tabular}

A factor analysis was performed to further break down eight of the ten statements into three factors. The test values of reliability (Cronbach Alpha) and quality of the model (Kaiser-Meyer-Oklin measure) were both at the marginal acceptable level (around .600) [24, 25]. The Bartlett's test of sphericity was also significant $(p<.01)$ [25]. Those factors accumulated $68.6 \%$ of total variances. Participants' ratings on each statement and identified factor related to revenue generation and gender equity were list in Table 3 . The three identified factors are: (1) fundamental beliefs (three items); (2) revenue sharing concepts (three items); and (3) revenue distribution practice (two items). In general, the factor of fundamental beliefs deals with how participants perceive the interscholastic programs. Revenue sharing concepts express 
how revenues should be shared between the male and female programs. The actual revenue distribution practice is views related to practice for distributing funds for programs. Overall, participants are favoring two specific statements: (1) female sports should receive same amount of funds as male sports $(M=1.37)$, and (2) male sports generate more revenue for our school than females' $(M=1.88)$. Yet surprisingly, they tended to disagree that all teams should share their revenue from fundraising equally $(\mathrm{M}=3.83)$.

The independent t-tests did not find significant differences on any of the identified factors based on gender. However, the test showed that male and female participants' ratings were significantly different for Question/Item No. $2(p<.05)$ and No. $8(p<.01)$. According to the correlation analysis, the rating score of revenue sharing concepts was negatively correlated with revenue distribution practices at a moderate correlation level $(r=-.323, p<.01)$

\section{Discussion and Conclusions}

In the review of literature, many popular revenue generating are anecdotally highlighted. The findings of this studies covered the majority of methods reported in the past literature. Our findings are consistent with the information found in past literatures regarding effective and most identified fundraising methods. Participants adopted both direct and indirect sales/services for athletic program funds (i.e., food and apparel sales, golf scramble and sponsorship sales, etc.). This small sample of participants in a unique Appalachian region had recognized methods that they would work well for their programs. Golf scrambles' impact was clearly recognized as it was documented in a few articles [7, 9, 10]. Sport camps, dinner events and sponsorship are the favorite choices that the participants would implement to generate funds in the future. This finding also coincides with the current trend. Charity events are recommended as great funding opportunities according to some coaches. Those coaches would like their players to involve in adopt-a-highway (trash pick-up), bingo, car wash, and various sales activities. They may require a lot of time and effort from everyone. Adopt-a-highway is an activity that is considered as the least profitable idea by the coaches, yet coaches still like to use it because it is a good team-building task for players.

A specific finding in this study differs from the identified trend concerning the popular methods for raising funds. Although more state sport federations have decided to charge participation fees to offset the costs, this idea was not popular among Kentucky survey respondents. Only seven participants mentioned the use of it as a fundraising method. Unlike many wealthy populous states have adopted this practice, perhaps charging participation fee in this not-so-wealthy geographical region could create a negative consequence in decrease of overall participation.

The open-ended comment revealed that importance of ADs' involvement in fundraisers. Fundraising should be a collaborate work, not a solo task placed on the coaching staff. This notion was evidently supported by the disapproval rating on Question $5(M=3.68)$ indicating that participants did not think coaches should be entirely responsible for fundraising without ADs' support.

In general, ADs of both genders did not exhibited significance difference on their ratings toward "revenue sharing concepts" and "revenue distribution practices." However, independent t-test analysis did further show that male and female participants' ratings were significantly different on Question/Item No. 2 and No. 8. It is not a surprise to see that female participants $(M=1.10)$ were more supportive to the statement of receiving the same amount of funding more than their male counterparts $(M=1.45)(p$ $<.05)$. On the other hand, the female athletic directors also know that fact that the large lucrative football program typically would bring more fundraising dollars and request more costs. Philosophically, it is noble to treat every male and female sport the same by giving out equal amount of funds. But this practice will not be easily implemented easily without criticisms.

The female participants significantly expressed that they were more likely to agree to conduct fundraising year round $(p<.01)$. The authors suspected that there could be two explanations behind this phenomenon. It may simply because that male ADs and coaches have invested too much time and energy in training and coaching, they would rather "take a break" during the off-season. Another explanation may be due to the consistent lack of funds for the female programs that cause female directors to worry more. Football and men's basketball often receive financial support more abundantly and frequently, so it is easy for others to assume that fundraising will be easy for those programs without requiring hard works.

Overall, the participants seemed to remain neutral on if male and female athletes should be competed together in the same sports $(M$ of $\mathrm{Q} 1=2.85)$. Although the predominant amount of participants is male ADs, they tended to stand on the affirmative side for issues such as female sports receiving equal funding and revenue should not stay within a specific team (see rating of Question 4). These are the positive results that exemplified the essence of Title IX concerning gender equality.

When further examining the rating of revenue distribution practices, then it clearly depicted that male ADs philosophically believed in one thing but were unconsciously doing things the other way.

The researchers assumed that participants' ratings on some of the related philosophical statements will be similar in values and correlated. Example of those grouped statements may include: (1) Q4 and Q10 and (2) Q2, Q6, and Q9. It would be ideal to see if the rating of revenue sharing concepts and revenue distribution practices can be positively correlated. Surprisingly, ratings of items that were grouped among themselves actually ended up with either a relatively low and insignificant correlation or a large discrepancy in value. For example, participants seemed to agree that female 
sports should receive the same amount of funding as male sports ( $M$ of $\mathrm{Q} 2=1.37$ ); however, the approval ratings on "all teams for both genders should share the revenues on an equal basis" (mean score of Q6 $=3.83$ ) and "sport sponsors should distribute their funding equally" (mean score of Q9 = 2.51) were worse. Both $\mathrm{Q} 4$ and $\mathrm{Q} 10$ statements were dealing with the concept of that a specific gender team or sport may have the right to retain its own funding without equally sharing with the other gender team. Ideally, they are statements that researchers would expect everyone to disapprove. The rating of Q4 clearly expressed that participants did not agree the fund can be kept by a specific team $(M=3.67)$. However, they were slightly favoring on sponsors should have the right to determine which gender team the money should go $(M=2.88)$. The correlation between Q4 and Q10 was fairly low and insignificant ( $r=$ $2.54 ; p>.05)$.

The results concluded that rating score of revenue sharing concepts was negatively correlated with revenue distribution practices at a moderate correlation level $(\mathrm{r}=-.323, \mathrm{p}<.01)$.

In addition, a couple of paired items (Q4 vs. Q6 and Q9 vs. Q10) that logically should have an inversed relationship on ratings turn out to be very similar. For example, participants would disagree that revenue can be kept within a specific team $(M=3.66)$. However, they did not strongly disapprove that sponsors can have the right to determine where the money may go ( $M=2.88$; this score is slightly toward to the agreeable side).

The researchers believe that the major contribution of our study is to demonstrate the conflict and paradox of maintaining a lofty social ideology (gender equity) under a pragmatic economic condition and operating culture that are male dominant and driven. The paradox was presented by the negative correlation between the revenue sharing concepts and revenue distribution practices. The participants may be willing to accept the notion of gender equity and agree to the concept of having equal distribution of athletic funds. However, they (particularly male participants) unconsciously insist that the raised funds should be retained and used for a specific sport. This logic is actually quite acceptable. In other words, when external sponsors and boosters decide to bring in money for football program, they may intend to keep their money only for the football, since they are not part of the school system and should not be held accountable for the Title IX requirement. It is easy for the players and coaches to assume that they deserve that every penny that they have raised for their program, because they have spent time and effort to raise those funds anyway. Since ADs and coaches were under the school system, abiding to Title IX compliance is an inevitable principle that they must achieve. Boosters of each sport team technically are not under the school system, is it necessary for them to comply to Title IX regulation as well? The paradox is if the football booster want to keep their raised fund strictly for the football program, how funds can be equally shared for both gender sports? In reality, it is really difficult to control boosters' activities, if there is no genuine consensus on the meaning of gender equity.

Welch proposed several useful tips to combat budget cuts of interscholastic athletic programs. In addition to maintain an accurate record of the needs, inventories, and costs, he further emphasize the necessity of seeking out parent support, conducting team fundraisers, and welcoming community donations and sponsorships [26]. These suggestions are in agreement with the findings of this study. The researchers strongly endorsed comments of Carpenter, Portman, and Witte while dealing with the Title IX compliance issues [27]. Administrators must be proactive to monitor booster clubs' donations. As one participant of the study has indicated, it may be a good idea to unify all of the boosters into one and allocate and distribute the funds centrally. ADs and coaches should pay attention to the law, such as "High School Athletic Accountability Act" and "The High School Sports Information Collection Act" (Carpenter et al, 2010). KHSAA's mandatory Title IX report and education workshops are effective tools for monitoring equity status and informing the public about the gender equity concerns.

Title IX has been established for more than 40 years. Gender equity should not just be a "spirit" or a "personal ethic" that no authority can enforce the compliance. Administrators cannot use the lack of funding as an excuse to dodge the responsibility of equity compliance. Simply making the sports available to both genders will help eliminate many gender discrimination legal lawsuits. We would like to conclude our thought with an analogy. The charge for all of the ADs and coaches is that they don't just provide the pie (programs), but need to divide the pie equally and fairly for both sons and daughters (students). The researchers of the present study would recommend the future researchers to expand the sample size on this type of gender and funding related study. It would be ideal if they can test and examine the responses on some of aforementioned controversial statements again. Hopefully, the term of gender equity would not be something that each individual can stretch and bend its meaning in order to satisfy subjective standard.

\section{REFERENCES}

[1] Kiely, K. (2005). Surveys can be used to show Title IX compliance. USA Today. 4C.

[2] Newell, K. (2002). The fun and profit in fundraising. Coach and Athletic Director, 72, 6; 42

[3] Pierce, D., \& Bussell, L. A. (2011). National survey of interscholastic sport sponsorship in the United States. Sport Management International Journal, 7(1), 43-62. D.O.I: http:dx.doi.org/10.4127/ch.2011.0054

[4] Savoye, C. (2000). Kentucky schools try to control private athletic funds to level gender playing field. Christian Science Monitor, 92(240), Retrieved from 
[5] Eitzen, S., \& Sage, G. (2013). Sociology of North American Sport (9th ed.). Boulder, CO: Paradigm Publishers.

[6] National Interscholastic Athletic Administrators Association (NIAAA). (2006). Survey provides new information on high school athletics. Retrieved from http://www.miaa.net/NIAAA-Survey-press-release.pdf

[7] Sawyer, T. H., \& Gimbert, T. (2012). Interscholastic athletics. In T. H. Sawyer \& Lawrence Judge (2012) (Eds). The management of fitness, physical activities, recreation, and sport. pp. 253-272. Champaign, Illinois: Sagamore Publishing.

[8] Searing, N. (2004). UA athletics keeps the games going. Inside Tucson Business, 14, 20.

[9] Unknown. (2002). Bringing fundraising to the FORE-front. Coach and Athletic Director, 72, 2-3, 50.

[10] Van Milligen, D. (2013). Fundraising ideas for high school athletic directors. Retrieved from http://www.athleticbusiness.com/fundraising/fundraising-ide as-for-high-school-athletic- directors.html?

[11] Yordy, B. (2010). Launching alternative revenue-generating programs: A case-study of Eastbrook Community School's athletic department. Unpublished Master's Creative Project. Ball State University: Muncie, IN.

[12] Howard, D. R., \& Crompton, J. (2013). Financing sports (3rd ed.). Morgantown, West Virginia: Fitness Information Technology.

[13] Forsythe, E. (2001). The sponsorship connection: A practical guide for high school athletic directors and coaches. Fayetteville, Arkansas: Athletic World Advertising.

[14] Bravo, G. A., \& Chellagurai, P. (2005). An investigation of stakeholder influence and institutional pressures on budget strategies in high school athletics. Future Focus, 26(1), 24-29.

[15] Hall, S. \& Gibson, A. (2008). Interscholastic sport sponsorship: Following in the footsteps of professional and collegiate sports? Mississippi Alliance for Health, Physical
Education, Recreation and Dance Journal. Retrieved from http://www.msahperd.com/ejournal/Manuscript-Interscholast icSportSponsorship.Pdf

[16] McKee, P. (2006, August 25). Name that field: Preps go corporate. The Indianapolis Star, A.1.

[17] Reeves, K. (2006). Sports at any cost? School Administrator, 63(6), 28-30.

[18] Lichtman, B. (1998). Sexual discrimination and school sports: the Title IX compliance challenge. USA Today Magazine, 126, 62-63.

[19] Kennedy, C. L. (2007). The athletic directors' dilemma: \$\$ \& women's sports. Gender Issues, 24, 34-45. DOI $10.1007 / \mathrm{s} 12147-007-9004-\mathrm{x}$

[20] Richey, W. (1997). Girls, boys, sports, and fairness. Christian Science Monitor, 89, 1-2.

[21] McRorie, J. (2001). High schools face scrutiny, lawsuits over gender equality sports teams. Curriculum Review, 41(3), 14-16.

[22] Lopiano, D. A. (2014). It's time for the NCAA and other educational sport governance organizations to get serious about gender equity. JOPERD, 85(2), 6-7.

[23] The Christian Century (2012). A new playing field. The Christian Century. 129(12), 7.

[24] DeVellis, R. E. (1991). Scale development: Theory and applications. London, England: SAGE.

[25] Wu, M. L. (1999). SPSS statistical applications. Taipei, Taiwan: Unalis Corporation.

[26] Welch, C. (2003). Coaching high school soccer on a limited budget. Coach \& Athletic Director, 73(4), 18.

[27] Carpenter, L. J., Portman' P. A., \& Witte, K. (2010). Title IX: Implications for secondary physical education and interscholastic sports. Papers presented at the 2010 Annual AAHPERD Convention, Indianapolis, Indiana. 